\title{
Perfil da toxicidade ao tratamento clínico com hidroxiureia em pacientes portadores de anemia falciforme no estado do Piauí
}

\author{
Profile of toxicity to clinical treatment with hydroxyurea in patients with anemia falciforme in \\ the state of Piauí
}
Perfil de la toxicidad al tratamiento clínico con hidroxiuria en pacientes portadores de anemia falciforme en el estado del Piauí
Wdson Magalhães Silva ${ }^{1 *}$, Wallyson André Dos Santos Bezerra², Eliamara Barroso Sabino Nogueira².

\begin{abstract}
RESUMO
Objetivo: Caracterizar o perfil clínico dos pacientes portadores de anemia falciforme acompanhados em uma unidade de assistência farmacêutica na cidade de Teresina - Piauí, que fazem uso da hidroxiureia (HU). Métodos: a metodologia do estudo iniciou-se com a análise do resultado de exames laboratoriais periódicos de 57 pacientes, observando os valores nominais e percentuais em função do controle dos índices hematológicos e bioquímicos em função do tempo de uso da droga, em trimestres durante o ano de 2015 e 2016. Resultados: Notou-se uma queda significativa dos valores nominais e percentuais comparados ao controle, nos valores de reticulócitos, leucócitos totais e plaquetas desde o $1^{\circ}$ trimestre analisado, e queda no $5^{\circ}$ trimestre de Hemácias e do hematócrito, como também queda nos valores de bilirrubina Total e frações e função do tempo. Notou-se também um aumento significativo nos valores de hemoglobina, hematócrito, VCM, HCM, RDW, TGP, TGO, ácido úrico e especialmente hemoglobina fetal (HbF). Conclusão: $O$ conhecimento do perfil da toxicidade mostrou ser uma importante ferramenta para melhora do manejo clinico de pacientes portadores de anemia falciforme em uso de $\mathrm{HU}$, por apresentar os principais parâmetros hematológicos e bioquímicos que sofrem influência direta do uso deste fármaco.
\end{abstract}

Palavras-chave: Anemia falciforme, Hidroxiureia, Toxicidade, Hemoglobina S, Hemoglobina fetal.

\begin{abstract}
Objective: To characterize the clinical profile of patients with sickle cell anemia followed in a pharmaceutical care unit in the city of Teresina - Piauí, who use hydroxyurea (HU). Methods: The study methodology began with the analysis of the results of periodic laboratory examinations of 57 patients, observing the nominal and percentage values as a function of the control of the hematological and biochemical indices as a function of the time of drug use, in quarters during the period. Results: There was a significant decrease in the nominal and percentage values compared to the control, in reticulocyte, total leukocyte and platelet values since the first quarter analyzed, and decrease in the 5th quarter of RBCs and hematocrit, as also decrease in Total bilirubin values and fractions and time function. A significant increase in hemoglobin, hematocrit, MCV, HCM, RDW, TGP, TGO, uric acid and especially fetal hemoglobin ( $\mathrm{HbF}$ ) values was also noted. Conclusion: Knowledge of the toxicity profile proved to be an important tool for improving the clinical management of patients with sickle cell anemia using $\mathrm{UH}$, as it presents the main hematological and biochemical parameters that are directly influenced by the use of this drug.
\end{abstract}

Keywords: Sickle cell anemia, Hydroxyurea, Toxicity, Hemoglobin S, Fetal hemoglobin.

${ }^{1}$ Faculdade Integral Diferencial (FACID-WYDEN), Teresina - PI. *E-mail: wdson.magalhaes@gmail.com. ${ }^{2}$ Centro Universitário UNINOVAFAPI, Teresina - PI.

SUBMETIDO EM: 10/2019

ACEITO EM: 11/2019

PUBLICADO EM: 2/2020

REAS/EJCH | Vol.Sup.n.40 | e2801 | DOI: https://doi.org/10.25248/reas.e2801.2020 Página 1 de 9 


\section{RESUMEN}

Objetivo: Caracterizar el perfil clínico de pacientes con anemia falciforme seguidos en una unidad de atención farmacéutica en la ciudad de Teresina - Piauí, que usan hidroxiurea (HU). Métodos: La metodología de estudio comenzó con el análisis de los resultados de exámenes periódicos de laboratorio de 57 pacientes, observando los valores nominales y porcentuales en función del control de los índices hematológicos y bioquímicos en función del tiempo de uso de drogas, en trimestres durante el período. Resultados: Hubo una disminución significativa en los valores nominales y porcentuales en comparación con el control, en valores de reticulocitos, leucocitos totales y plaquetas desde el primer trimestre analizado, y disminución en el quinto trimestre de glóbulos rojos y hematocrito, como También disminuyen los valores totales de bilirrubina y las fracciones y la función del tiempo. También se observó un aumento significativo en los valores de hemoglobina, hematocrito, MCV, HCM, RDW, TGP, TGO, ácido úrico y especialmente hemoglobina fetal $(\mathrm{HbF})$. Conclusión: El conocimiento del perfil de toxicidad demostró ser una herramienta importante para mejorar el manejo clínico de los pacientes con anemia de células falciformes usando $\mathrm{UH}$, ya que presenta los principales parámetros hematológicos y bioquímicos que están directamente influenciados por el uso de este medicamento.

Palabras clave: Anemia falciforme, Hidroxiurea, Toxicidad, Hemoglobina S, Hemoglobina fetal.

\section{INTRODUÇÃO}

A anemia Falciforme é uma doença hereditária de maior prevalência no Brasil e no mundo. "No Brasil, estima-se o nascimento de 3.500 crianças com anemia falciforme (AF) por ano, uma em cada mil recémnascidos vivos". De acordo com Soares LF, et al. (2014), a doença falciforme é considerada um problema de saúde pública; e os indivíduos que apresentam a Hemoglobina S (HbS) em homozigose evidenciam uma condição grave da doença, enquanto indivíduos com a HbS em heterozigose (chamado também de "traço falciforme"), não apresentam manifestações clínicas, conferindo uma vida normal ao seu portador.

A conformação anormal das hemácias é a principal causa de diminuição do seu tempo de vida. Quando diminui o oxigênio na circulação, as hemácias com a hemoglobina $S$ podem ficar com a forma de meia lua ou foice, perdem a mobilidade, por esse motivo têm dificuldade para passar pelos vasos sanguíneos, formando um aglomerado de glóbulos vermelhos que impede a circulação do sangue e o oxigênio para os tecidos e órgãos (SANTOS BSC, 2011).

O diagnóstico de anemia falciforme conforme Brasil (2012), sé dá por meio laboratorial da anemia falciforme é realizado pela detecção da $\mathrm{HbS}$ e da sua associação com outras frações, por meio de eletroforese em agarose ou celulose em meio alcalino, ou também triagem neonatal realizada na primeira semana de vida da criança em sangue total colhido do calcanhar, por eletroforese de hemoglobina feita por Cromatografia líquida de alta eficiência (HPLC) ou focalização isoelétrica. Em ambos os casos, sempre deve estar acompanhado o hemograma. Quanto ao tratamento, a droga mais utilizada para o controle dos sintomas da doença é a hidroxiureia $(\mathrm{HU})$.

A hidroxiureia, de acordo com Brasil (2013), possui vários efeitos diretos no mecanismo fisiopatológico da anemia falciforme, atuando não só no aumento da síntese da Hemoglobina Fetal (HbF), o que reduz a polimerização intraeritrocitária da $\mathrm{HbS}$ em condições de desoxigenação, como também promove diminuição do número dos neutrófilos, hidratação eritrocitária, redução da expressão de moléculas de adesão dos eritrócitos, aumento da síntese e biodisponibilidade de óxido nítrico pela ativação da guanilil ciclase e consequente aumento da GMP cíclico intraeritrocitária e endotelial. Levando em consideração a problemática questionada e as eventuais potencialidades, o presente estudo tem como objetivo caracterizar o perfil clínico dos pacientes portadores de anemia falciforme acompanhados em uma unidade de assistência farmacêutica na cidade de Teresina - Piauí, que fazem uso da hidroxiureia.

\section{MÉTODOS}

Esse estudo foi iniciado após submissão e aprovação do Comitê de Ética em Pesquisa (CEP) com o número de registro 66011417.7.0000.5211, além de ele ser pautado na resolução 466/12. Trata-se de um estudo quantitativo, retrospectivo, observacional descritivo documental e transversal. 
Os sujeitos da pesquisa foram 57 prontuários e resultados de exames de pacientes portadores de anemia Falciforme de ambos os sexos, que são acompanhados em Unidade de Assistência Farmacêutica da rede pública da cidade de Teresina, estado do Piaú, e que fizeram uso da hidroxiureia durante o ano de 2015 e 2016, seguindo os pré-requisitos de acordo com a Portaria n 55/2010 do Ministério da Saúde (MS) e que se enquadraram nos critérios de inclusão e exclusão da pesquisa.

A coleta de dados foi realizada por meio de observação e registro em um formulário de elaboração própria para a pesquisa, denominado Formulário de Acompanhamento de Dados Laboratoriais, baseado nos exames laboratoriais necessários para a monitorização preconizada pela Portaria n 55/2010 do Ministério da Saúde (MS), no qual registraram-se os resultados dos valores dos exames laboratoriais obtidos no banco de dados dos pacientes atendidos pela instituição no município de Teresina-PI.

Após coletados, os dados foram organizados em uma Tabela do Microsoft Excel $2013^{\odot}$, onde observouse valores nominais e percentuais e desvio padrão dos seguintes aspectos: Idade; Sexo; Parâmetros Hematimétricos da Série Vermelha; Parâmetros Hematimétricos da Série Branca; Parâmetros Bioquímicos.

O nível de significância adotado será $p \leq 0,05$ e o nível de confiança será de $95 \%$. Em seguida, os resultados foram apresentados em forma de Gráficos e Tabelas, exportados para exposição em documento redigido por Microsoft Word $2013^{\odot}$. Para traçar um perfil toxicológico do uso deste fármaco, foi avaliado a diferença dos valores comparada com da média do valor dos exames controle por trimestre $O$ pacote estatístico utilizado foi o programa GraphPad Prism $7^{\odot}$.

\section{RESULTADOS}

Após a aplicação dos critérios de inclusão e exclusão, obteve-se a amostra da população a ser analisada de 57 prontuários com resultados de exames laboratoriais. A idade dos pacientes variou de 4 a 40 anos, apresentando idade média de 15,28 anos. A mediana foi equivalente a 11 anos e a Moda, 8 anos. Observouse grande prevalência de indivíduos de até 21 anos, com raros indivíduos na $3^{\underline{a}}$ e $4^{\underline{a}}$ década de vida (Gráfico 1).

Gráfico 1 - Distribuição dos pacientes analisados por idade

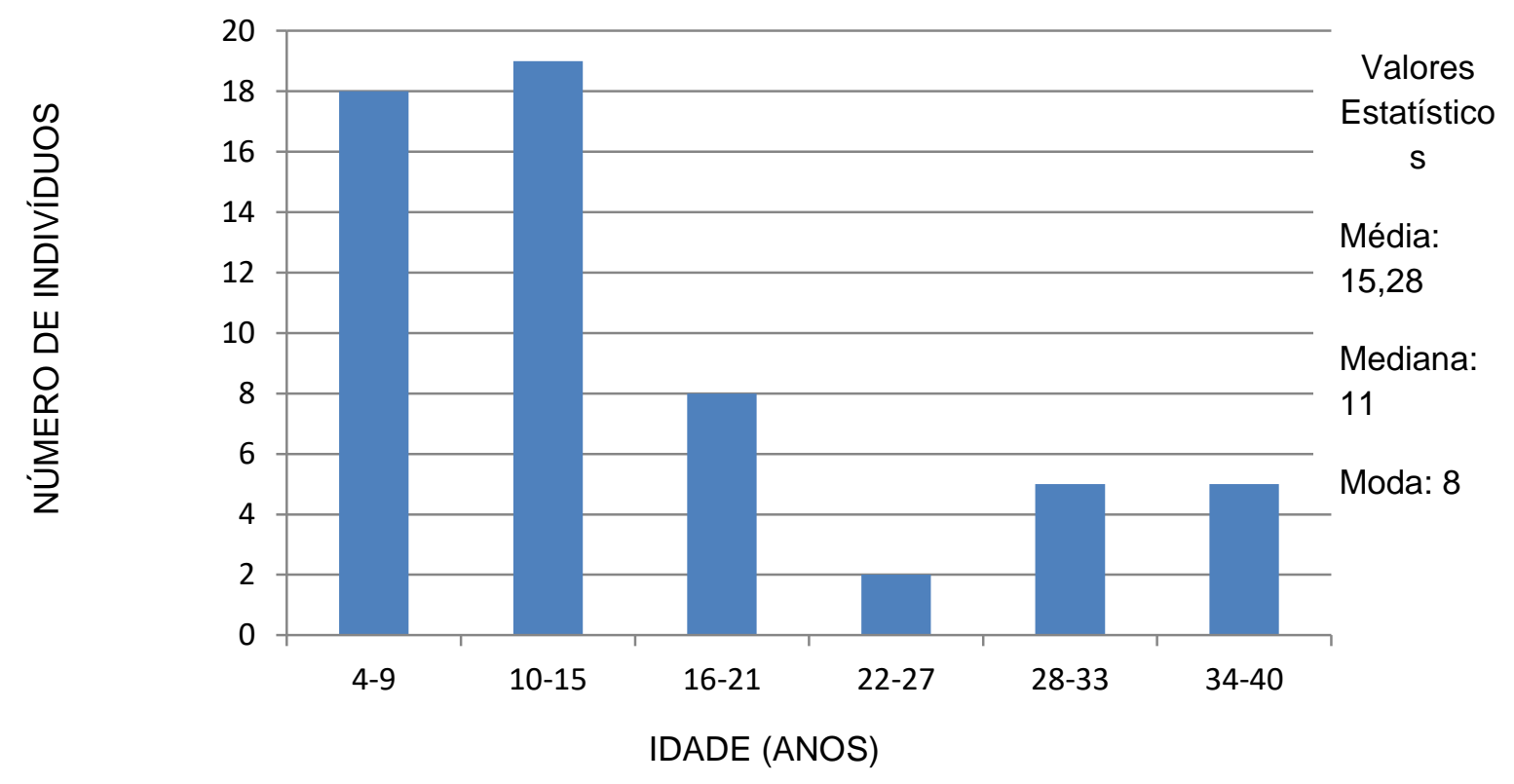

Fonte: Silva WM, et al., 2017

Quanto ao sexo dos indivíduos, dos 57 pacientes analisados e incluídos na pesquisa, 36 deles $(63,16 \%)$, eram do sexo masculino, e 21 (36,84\%) era do sexo feminino. Quanto ao resultado das médias dos valores nominais da Série Vermelha, encontrou-se disponível dados apenas até o 5o trimestre de uso da droga. 
Desses, observou-se a presença de variações em função do tempo em todos os índices Hematimétricos analisados, em especial no número de Reticulócitos, Índice de Anisocitose (RDW) e Concentração de Hemoglobina Corpuscular Média HCM). No entanto, foi observada pequena variação percentual ao longo dos trimestres com o número de hemácias (Tabela 1).

Tabela 1 - Valores nominais dos Índices Hematimétricos analisados, em função do tempo (por trimestre).

\begin{tabular}{|c|c|c|c|c|c|c|}
\hline \begin{tabular}{|l} 
\\
Parâmetro \\
\end{tabular} & Controle & $1^{\circ}$ & $2^{\circ}$ & $3^{\circ}$ & $4^{\circ}$ & $5^{\circ}$ \\
\hline $\begin{array}{c}\text { Hemácias } \\
\text { (milhões/mm³) } \\
\text { Desvio padrão }\end{array}$ & $\begin{array}{c}2,76 \\
\pm 0,66\end{array}$ & $\begin{array}{c}2,66 \\
\pm 0,56\end{array}$ & $\begin{array}{c}2,78 \\
\pm 0,65\end{array}$ & $\begin{array}{c}2,73 \\
\pm 0,55\end{array}$ & $\begin{array}{c}2,82 \\
\pm 0,71\end{array}$ & $\begin{array}{c}2,68 \\
\pm 0,22\end{array}$ \\
\hline $\begin{array}{c}\text { Hemoglobina (g/dL) } \\
\text { Desvio padrão }\end{array}$ & $\begin{array}{c}8,03 \\
\pm 1,50\end{array}$ & $\begin{array}{c}8,48 \\
\pm 1,69\end{array}$ & $\begin{array}{c}8,63 \\
\pm 1,54\end{array}$ & $\begin{array}{r}8,68 \\
\pm 1,56\end{array}$ & $\begin{array}{c}8,62 \\
\pm 1,50\end{array}$ & $\begin{array}{c}8,10 \\
\pm 1,18\end{array}$ \\
\hline Hematócrito (\%) Desvio & 23,80 & 25,51 & 26,01 & 25,58 & 25,49 & 22,57 \\
\hline padrão & $\pm 4,73$ & $\pm 5,49$ & $\pm 5,01$ & $\pm 4,82$ & $\pm 4,74$ & $\pm 1,96$ \\
\hline VCM (fL) & 88,12 & 96,63 & 94,90 & 96,13 & 93,00 & 96,58 \\
\hline Desvio padrão & $\pm 10,51$ & $\pm 14,74$ & $\pm 12,95$ & $\pm 12,59$ & $\pm 17,77$ & $\pm 10,10$ \\
\hline HCM (pg & 29,58 & 32,38 & 31,94 & 32,07 & 31,56 & 33,49 \\
\hline Desvio padrão & $\pm 3,62$ & $\pm 4,42$ & $\pm 4,41$ & $\pm 4,43$ & $\pm 6,20$ & $\pm 4,49$ \\
\hline CHCM (g/dL) & 33,51 & 33,64 & 33,22 & 33,85 & 33,83 & 34,61 \\
\hline Desvio padrão & $\pm 1,80$ & $\pm 2,39$ & $\pm 2,03$ & \pm 2.31 & $\pm 2,54$ & $\pm 2,25$ \\
\hline $\begin{array}{c}\text { RDW (\%) } \\
\text { Desvio padrão }\end{array}$ & $\begin{array}{l}18,27 \\
+2,80\end{array}$ & $\begin{array}{r}19,67 \\
+3,74\end{array}$ & $\begin{array}{r}19,30 \\
+3,22\end{array}$ & $\begin{array}{r}20,28 \\
+10,81\end{array}$ & $17,34 \pm 4,62$ & $20,04 \pm 4,49$ \\
\hline Reticulócitos (\%) & $\begin{array}{l}13,51 \\
+115\end{array}$ & $\begin{array}{r}8,01 \\
+6,02\end{array}$ & $\begin{array}{r}8,73 \\
+6,37\end{array}$ & $\begin{array}{c}-1,83 \\
+486\end{array}$ & $\begin{array}{r}8,36 \\
+506\end{array}$ & 7,28 \\
\hline
\end{tabular}

Fonte: Silva WM, et al., 2017

Quanto à variação percentual em relação ao controle em função do tempo nos dados da série vermelha, nota-se variação significante do número de reticulócitos, do RDW e especialmente no $1^{\circ}$ trimestre, do $\mathrm{CHCM}$. O Gráfico ainda mostra uma variação mais intensa do hematócrito e da hemoglobina. Quanto ao número de hemácias, observa-se oscilações discretas até o $4^{\circ}$ trimestre, e uma queda acentuada no $5^{\circ}$ trimestre. Os demais valores tiveram variação discreta nos demais trimestres (Gráfico 2).

Gráfico 2 - Variação percentual em relação ao controle em função do tempo nos dados da série vermelha.

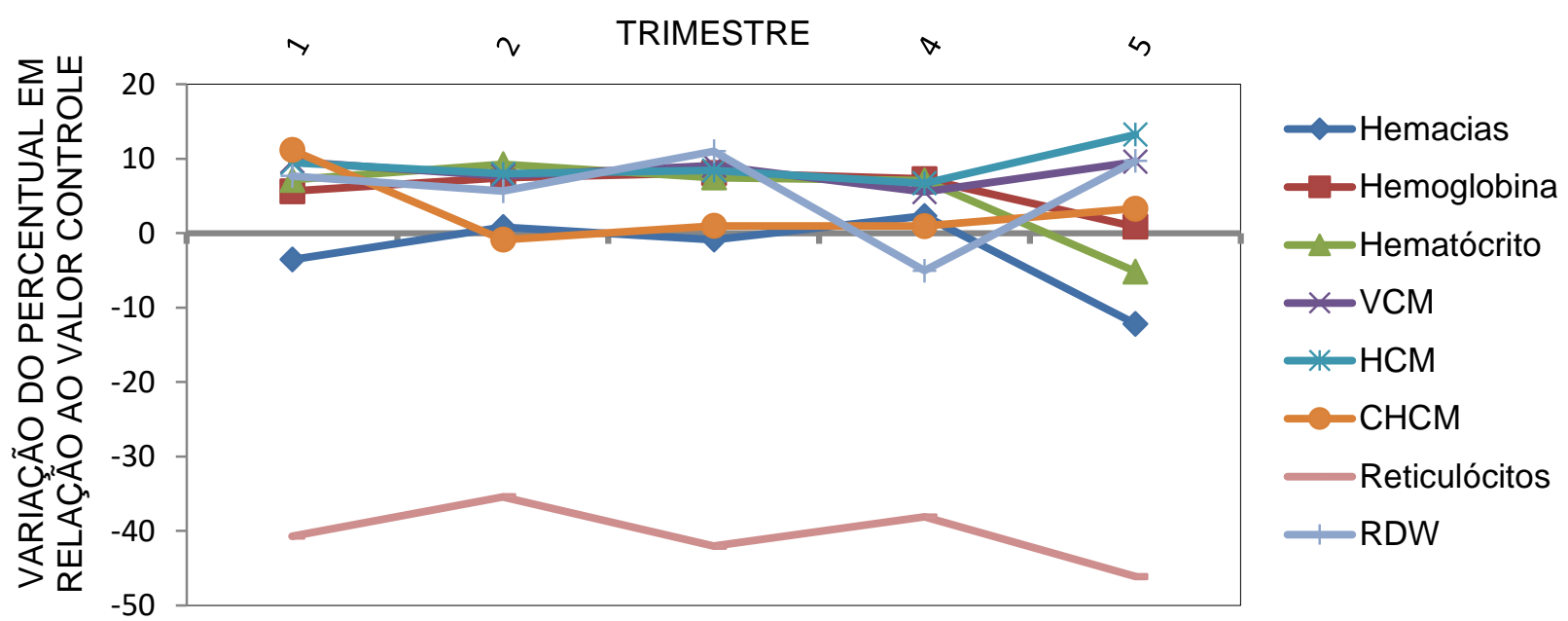

Fonte: Silva WM, et al., 2017

Observando os resultados dos dados da Série Branca, também se encontrou disponível dados apenas até o 50 trimestre de uso da droga. Quanto aos leucócitos, houve redução do seu valor nominal até o $4^{\circ}$ trimestre, com um aumento no número de leucócitos no 5 o trimestre. Quanto ao número de plaquetas, observou-se o mesmo padrão de comportamento: queda dos valores nominais até o $4^{\circ}$ trimestre e aumento dos valores no $5^{\circ}$ trimestre (Tabela 2). 
Observando os resultados dos dados da Série Branca, também se encontrou disponível dados apenas até o $5^{\circ}$ trimestre de uso da droga. Quanto aos leucócitos, houve redução do seu valor nominal até o $4^{\circ}$ trimestre, com um aumento no número de leucócitos no $5^{\circ}$ trimestre. Quanto ao número de plaquetas, observou-se o mesmo padrão de comportamento: queda dos valores nominais até o $4^{\circ}$ trimestre e aumento dos valores no 5o trimestre (Tabela 2).

Tabela 2 - Valores nominais do número de leucócitos e de plaquetas analisados, em função do tempo (por trimestre).

\begin{tabular}{c|cccccc}
\hline Trimestre & \multirow{2}{*}{ Controle } & $\mathbf{1}$ & $\mathbf{2}$ & \multirow{2}{*}{} & $\mathbf{4}$ & 5o \\
Parâmetro & & & & & & \\
\hline Leucócitos $\left(/ \mathrm{mm}^{3}\right)$ & 11195,96 & 10297,51 & 9243,10 & 8811,79 & 8375,91 & 9102,44 \\
Desvio padrão & $\pm 3839,47$ & $\pm 4099,59$ & $\pm 2889,83$ & $\pm 3075,44$ & $\pm 2209,39$ & $\pm 2826,83$ \\
Plaquetas & 429,39 & 398,51 & 347,87 & 333,94 & 314,14 & 352,67 \\
$\left(\times 100 / \mathrm{mm}^{3}\right)$ & $\pm 183,20$ & $\pm 148,05$ & $\pm 123,71$ & $\pm 115,18$ & $\pm 110,78$ & $\pm 92,04$ \\
Desvio padrão & & & &
\end{tabular}

Fonte: Silva WM, et al., 2017

Quanto à variação percentual em relação ao controle em função do tempo nos dados da série branca, observou-se um padrão de queda, se comparado ao valor controle, em ambos os parâmetros analisados. Tal padrão persiste até o 4ํㅡㄹ trimestre, quando os índices começam a aumentar novamente no $5^{\circ}$ semestre.

Quanto ao resultado dos dados dos parâmetros bioquímicos, em alguns parâmetros encontrou-se disponível dados apenas até o $4^{\circ}$ trimestre de uso da droga, enquanto que para outros, estava disponível dados até o 5 trimestre. Em alguns casos, como o da Desidrogenase láctica (DHL), havia dados sobre seu valor em menos de $20 \%$ dos prontuários analisados, o que inviabilizou a coleta de dados para tal parâmetro.

Tabela 3 - Valores nominais dos parâmetros bioquímicos analisados, em função do tempo (por trimestre).

\begin{tabular}{|c|c|c|c|c|c|c|}
\hline Parâmetro & Controle & $1^{0}$ & $2^{\circ}$ & 3 은 & $4^{\circ}$ & $5^{\circ}$ \\
\hline $\begin{array}{l}\text { Bilirrubina Total } \\
\text { Desvio padrão }\end{array}$ & $\begin{array}{r}3,85 \\
\pm 3,33\end{array}$ & $\begin{array}{r}2,99 \\
\pm 2,05\end{array}$ & $\begin{array}{c}4,00 \\
\pm 2,95\end{array}$ & $\begin{array}{c}3,22 \\
\pm 1,72\end{array}$ & $\begin{array}{c}2,61 \\
\pm 1,11\end{array}$ & $* *$ \\
\hline $\begin{array}{l}\text { Bilirrubina Direta } \\
\text { Desvio padrão }\end{array}$ & $\begin{array}{c}1,14 \\
\pm 0,75\end{array}$ & $\begin{array}{c}0,74 \\
\pm 0,52\end{array}$ & $\begin{array}{c}0,81 \\
\pm 0,43\end{array}$ & $\begin{array}{c}0,97 \\
\pm 0,56\end{array}$ & $\begin{array}{c}0,85 \\
\pm 0,43\end{array}$ & $* *$ \\
\hline $\begin{array}{c}\text { Bilirrubina } \\
\text { Indireta Desvio } \\
\text { padrão }\end{array}$ & $\begin{array}{c}2,87 \\
\pm 3,32\end{array}$ & $\begin{array}{l}2,31 \\
\pm 2,07\end{array}$ & $\begin{array}{c}3,04 \\
\pm 2,99\end{array}$ & $\begin{array}{c}2,29 \\
\pm 1,34\end{array}$ & $\begin{array}{r}1,76 \\
\pm 1,04\end{array}$ & $* *$ \\
\hline $\begin{array}{c}\text { Creatinina } \\
\text { Desvio padrão }\end{array}$ & $\begin{array}{c}0,45 \\
\pm 0,19\end{array}$ & $\begin{array}{c}0,50 \\
\pm 0,17\end{array}$ & $\begin{array}{c}0,49 \\
\pm 0,20\end{array}$ & $\begin{array}{c}0,45 \\
\pm 0,14\end{array}$ & $\begin{array}{c}0,47 \\
\pm 0,16\end{array}$ & $\begin{array}{c}0,48 \\
\pm 0,14\end{array}$ \\
\hline $\begin{array}{c}\text { ALT } \\
\text { Desvio padrão }\end{array}$ & $\begin{array}{c}20,81 \\
\pm 15,84 \\
\end{array}$ & $\begin{array}{r}23,38 \\
\pm 11,88 \\
\end{array}$ & $\begin{array}{r}28,65 \\
\pm 17,46 \\
\end{array}$ & $\begin{array}{l}23,84 \\
\pm 9,64 \\
\end{array}$ & $\begin{array}{r}33,16 \\
\pm 16,34 \\
\end{array}$ & $\begin{array}{r}36,00 \\
\pm 19,35 \\
\end{array}$ \\
\hline Parâmetro & Controle & $1^{0}$ & $2^{\circ}$ & 3 & $4^{\circ}$ & 5ㅇ \\
\hline $\begin{array}{c}\text { AST } \\
\text { Desvio padrão }\end{array}$ & $\begin{array}{r}42,80 \\
\pm 18,72\end{array}$ & $\begin{array}{c}44,27 \\
\pm 22,72\end{array}$ & $\begin{array}{c}52,48 \\
\pm 20,84\end{array}$ & $\begin{array}{c}50,36 \\
\pm 17,67\end{array}$ & $\begin{array}{c}55,18 \\
\pm 19,57\end{array}$ & $\begin{array}{c}65,62 \\
\pm 38,97\end{array}$ \\
\hline $\begin{array}{l}\text { Ácido Úrico } \\
\text { Desvio padrão }\end{array}$ & $\begin{array}{c}4,36 \\
\pm 1,11\end{array}$ & $\begin{array}{r}4,59 \\
\pm 1,26\end{array}$ & $\begin{array}{c}4,62 \\
\pm 1,93\end{array}$ & $\begin{array}{c}4,68 \\
\pm 1,75\end{array}$ & $\begin{array}{c}5,26 \\
\pm 0,90\end{array}$ & $* *$ \\
\hline $\begin{array}{c}\text { Hemoglobina } \\
\text { Fetal } \\
\text { Desvio padrão }\end{array}$ & $\begin{array}{c}9,11 \\
\pm 8,42\end{array}$ & $\begin{array}{l}10,54 \\
\pm 7,92\end{array}$ & $\begin{array}{l}13,36 \\
\pm 7,73\end{array}$ & $\begin{array}{r}15,68 \\
\pm 10,09\end{array}$ & $\begin{array}{l}14,96 \\
\pm 9,18\end{array}$ & $\begin{array}{r}20,95 \\
\pm 14,21\end{array}$ \\
\hline
\end{tabular}

Fonte: Silva WM, et al., 2017 
Quanto à variação percentual em relação ao controle em função do tempo dos parâmetros bioquímicos, observou-se um significativo aumento dos dados das transaminases alanina aminotransferase (ALT) e transaminase oxalacética (AST) e especialmente da HbF. Também foi observado um discreto aumento das provas de função renal (Ureia e Creatinina). Observou-se queda nos valores de Bilirrubina, tanto Total, como suas frações (direta e Indireta). Como citado anteriormente, devido à baixa disponibilidade dos dados sobre a lactato desidrogenase (DHL), não foi possível estabelecer um padrão de variação percentual para tal marcador.

\section{DISCUSSÃO}

A hidroxiureia vem sendo indicada com sucesso para o controle das crises álgicas causadas pelo fenômeno de vasoclusão em pacientes portadores de anemia falciforme. No entanto, de acordo com Brunton LL e Goodman G (2012), a droga tem como efeito adverso apresentar depressão hematopoiética, incluindo leucopenia, anemia megaloblástica, como também podendo causar trombocitopenia.

Quanto à idade média dos pacientes, Brasil (2010) afirma que a sobrevida mediana dos homens com DF era de 42 anos e a das mulheres de 48 anos. No Gráfico 1, observa-se a idade média dos pacientes em tratamento (15,28 anos) dentro dessa taxa de sobrevida, bem como a mediana (11 anos) e a moda (8 anos). $O$ fato da prevalência de pacientes mais jovens, com grande maioria abaixo de 21 anos, pode ser relacionado a melhorias do diagnostico laboratorial pelo programa de Triagem neonatal, que segundo Brasil (2012), o estado do Piauí foi incluído na fase IV do programa no ano de 2012. Martins MS, et al. (2010), ressalta a importância de se considerar a aplicação cuidados paliativos de forma efetiva sobre a doença falciforme para a melhoria da qualidade de vida desses pacientes, visto pelo tempo do diagnostico pra crises álgicas.

Quanto à distribuição pelo sexo dos pacientes, conforme Furtado NA, et al. (2015), a doença falciforme não é uma doença hereditária relacionada ao sexo do indivíduo. Logo não há justificativa na literatura para uma maior prevalência em indivíduos do sexo masculino ou feminino. Nos resultados obtidos observou-se maior prevalência em indivíduos do sexo masculino $(63,16 \%)$, homens. Uma justificativa para tal resultado pode estar ligada ao tamanho da amostra avaliada (57 indivíduos) em relação à prevalência nacional da doença, o que explica os dados estarem sujeitos a variações estatísticas, fugindo da média nacional.

Quanto à variação dos parâmetros da série vermelha, observamos a queda nos valores nominais das hemácias já no 1ํo trimestre de uso da droga $\left(2,66\right.$ milhões $\left./ \mathrm{mm}^{3}\right)$ em relação ao controle $\left(2,76 \mathrm{milhões} / \mathrm{mm}^{3}\right)$ (Tabela 1), bem como nos valores percentuais (Gráfico 2). No entanto, os dados oscilaram entre os trimestres, mostrando uma queda intensa desse valor apenas a partir do $5^{\circ}$ semestre (diferença de $12 \%$ em relação ao controle). Segundo Bispo (2013), alterações eritrocitárias causadas por conta dos efeitos da HU promovem o aumento do hematócrito e da hemoglobina, bem como a hidratação e a sobrevida das hemácias. Tal fato justifica o aumento nos valores de eritrócitos, se comparados ao controle, como também o aumento observado, em todos os trimestres, da hemoglobina e do hematócrito. Quanto a queda do número de hemácias observada no $5^{\circ}$ semestre, esta pode estar associada à falha terapêutica por conta da má adesão ao tratamento, ou ao fenômeno de sequestro esplênico.

Quanto à variação do Volume Corpuscular Médio (VCM), nota-se o aumento nos valores médios (Tabela 1) e também nos percentuais, se comparado ao controle, em todos os trimestres analisados (Gráfico 2). Tal fato era esperado, devido ao mecanismo de ação da droga, pois conforme Brunton LL e Goodman G (2012), a HU promove bloqueio da síntese do ácido desoxirribonucleico (DNA) pela inibição da ribonucleotídeo redutase, mantendo as células em fase $S$ do ciclo celular. Sem a divisão celular, a célula estaciona seu ciclo na intérfase, o que ocasiona o aumente do VCM. Tal fenômeno foi observado nos estudos de Silva-Pinto AC, et al. (2013) e de Bispo IMGP (2013).

Ao avaliar a variação da hemoglobina corpuscular média (HCM), nota se um aumento dos valores nominais (Tabela 1), como também aumento no valor percentual em relação ao controle (Gráfico 2) em todos os trimestres avaliados. Como citado antes, pelos estudos de Bispo IMGP (2013), a hidroxiureia induz a um aumento nos níveis tanto do hematócrito como os níveis de hemoglobina no interior das hemácias, o que consequentemente induz o aumento de HCM. Observando os valores de Concentração de Hemoglobina Corpuscular Média ( $\mathrm{CHCM}$ ), pode-se visualizar que inicialmente, há um aumento dos valores médios 
nominais (Tabela 1), como também percentuais desse parâmetro no $1^{\circ}$ trimestre, mas nos trimestres subsequentes há estabilização do valor próximo ao valor controle (Gráfico 2).

Segundo Souza JM, et al. (2016), a deformação dos eritrócitos discóides em forma falcizada altera a funcionalidade da bomba de sódio e potássio, com consequência a perda de potássio e água, tornando os eritrócitos mais densos e favorecendo o acúmulo de $\mathrm{HbS}$, provocando a elevação da concentração intracelular de cálcio, pela perda da bomba de cálcio/ATPase, dos íons monovalentes, e aumenta os valores de CHCM. Com o uso da hidroxiureia, ocorre redução do $\mathrm{CHCM}$, porém essa redução tende a ser discreta, pois segundo Gomes IBS (2003) o CHCM é o quociente dos valores de hemoglobina sobre o hematócrito; como ambos se encontraram elevados, a razão tende a ser próxima do valor normal.

Neste trabalho, também se buscou avaliar o red cell distribuition width (RDW), conhecido também como Índice de anisocitose, onde observou-se aumento dos valores tanto nominais (Tabela 1) como percentuais em relação ao controle, em função do tempo (Gráfico 2); exceto o dado observado no $4^{\circ}$ trimestre, onde notase uma queda do valor do RDW em relação ao padrão.

De acordo com Leal KST, et al. (2015), o RDW é um coeficiente de variação da distribuição das hemácias, ou seja, é um indicativo do grau de anisocitose das hemácias expresso em porcentagem; é determinado dividindo o desvio padrão do VCM pelo VCM e multiplicando por 100, convertendo-se assim o valor em porcentagem.

Como visto, o RDW depende diretamente do valor de VCM, então se espera que tal parâmetro também apresentasse em níveis aumentados. O valor abaixo do controle no $4^{\circ}$ trimestre pode ser justificado pela presença de sequestro esplênico em alguns indivíduos, visto que nesse caso, as células mais anormais ficariam presas na rede reticular no baço, conferindo uma falsa redução no grau de anisocitose.

Um dos maiores impactos avaliados nos resultados desse trabalho se dá na queda dos valores de reticulócitos. Nos resultados obtidos, houve queda dos valores nominais, se relacionados com o controle (Tabela 1); e foi observada a queda também na variação percentual em função do tempo, mas nota-se que esta foi maior variação de todos os parâmetros avaliados (Gráfico 2). Tal fato já era esperado, pois, de acordo com Santos BSC (2011), sabe-se que a HU, pelo seu mecanismo de ação, é capaz de induzir queda no número de reticulócitos.

A HU também teve efeitos sobre a linhagem das células brancas. Ao analisar os dados obtidos da variação os leucócitos, observa-se queda nos valores nominais em todos os semestres, com uma queda menos acentuada apenas no $5^{\circ}$ semestre (Tabela 2). Quanto à variação percentual em função do tempo, nota-se a queda dos valores, quando comparados ao número de leucócitos no exame controle. Tal comportamento é explicado pelo efeito mielotóxico da droga. "Entre população pediátrica há relatos de surgimento de mielotoxicidade, principalmente plaquetopenia e neutropenia, durante o uso da medicação, porém, na sua maioria reversível após suspensão da droga" (SILVA MC e SHIMAUTI ELT, 2006).

Quanto aos dados referentes ao número de plaquetas, observa-se um padrão bastante semelhante ao dos leucócitos: queda nos valores nominais em todos os semestres, queda menos acentuada no $5^{\circ}$ semestre (Tabela 2). Quanto à variação percentual em função do tempo, o padrão se repete na linhagem das plaquetas; nota-se a queda dos valores, quando comparados ao número de leucócitos no exame controle.

A redução na contagem de plaquetas é também esperada, visto que a $\mathrm{HU}$ também é indutora de plaquetopenia, sobretudo em crianças. Silva-Pinto AC, et al. (2013), indica a plaquetopenia induzida pela HU como um dos mecanismos concorrentes de melhora clínica nesses pacientes.

A pesquisa também investigou alguns dados bioquímicos laboratoriais. De acordo com Brasil (2010), para o início e acompanhamento do uso da $\mathrm{HU}$ nos pacientes com AF, além do hemograma completo e contagem de reticulócitos, é obrigatório o acompanhamento com as dosagens séricas de Uréia, creatinina, das transaminases pirúvica e oxalacética (TGP e TGO), Desidrogenase Láctica (DHL), Ácido úrico e Eletroforese de proteínas, a fim de avaliar a dosagem de HbF.

No entanto, em alguns parâmetros, só foi possível obter dados até o $4^{\circ}$ trimestre, e no caso dos dados da DHL, em cerca de $80 \%$ dos prontuários analisados, não foi encontrado nenhum valor mensurado, o que inviabilizou a análise dos dados disponíveis para tal parâmetro bioquímico (Tabela 3). 
Tal fato se dá pela dificuldade dos pacientes em realizar os exames laboratoriais, por conta de dificuldades do acesso aos serviços públicos de saúde, como também pelo impacto negativo dos custos dos exames no orçamento familiar, pois de acordo com Araújo, 2011, em torno de 76,3\% dos pacientes portadores de anemia falciforme no estado do Piauí ganham entre 1 a 3 salários mínimos mensais, dificultando ainda mais a realização dos exames laboratoriais pela rede privada. Analisando os dados obtidos sobre a bilirrubina, notase que só foi possível avaliar tal parâmetro até o $4^{\circ}$ trimestre, no entanto, é possível observar uma queda nos valores nominais, tanto da forma direta como da forma indireta, com exceção do $2^{\circ}$ trimestre, onde os resultados revelam um aumento da fração indireta, o que ocasionou um aumento dos níveis de bilirrubina total (Tabela 3).

Quanto aos valores referentes à variação percentual em função do tempo, o padrão é semelhante ao dos valores nominais: queda nos valores de bilirrubina total e suas frações nos trimestres avaliados em relação ao controle, com aumento apenas no $2^{\circ}$ trimestre dos valores de bilirrubina indireta e Bilirrubina Total. Conforme Laurentino MR (2016), a Bilirrubina é o principal metabólito do grupo heme e cerca de $70 \%$ são provenientes da destruição de hemácias senescentes. $\mathrm{Na} \mathrm{AF}$, ocorre a destruição precoce dos eritrócitos elevando a concentração de bilirrubina total, por conta do aumento dos níveis de bilirrubina indireta.

Segundo Silva MC e Shimauti ELT (2006), como também Bispo IMGP (2013), um dos impactos do uso da HU é a redução das taxas de Bilirrubina total como suas frações. Quanto ao aumento dos valores observados no $2^{\circ}$ trimestre, tal fato pode estar relacionado a eventos hemolíticos, visto que há um aumento da Bilirrubina indireta, que consequentemente induz o aumento dos níveis de bilirrubina total.

Quanto às provas de função Renal (Creatinina e Uréia), observou-se discreta variação (inferior a 10\%) tanto nos valores nominais (Tabela 3), como percentuais desses dois marcadores renais. Isso sugere que não há impacto significativo de toxicidade renal. Segundo Brunton LL e Goodman G (2012), a HU é excretada pela urina, e quanto a toxicidade renal, não há estudos suficientes que indiquem uma correlação.

Ao analisar as transaminases, observamos elevação dos valores nominais e percentuais dos níveis tanto da ALT como da AST (Tabela 3), tanto que no $5^{\circ}$ trimestre, o aumento da AST chegou a mais de $50 \%$ e o da ALT a quase $80 \%$, em relação ao controle. Tal fato é esperado, pois Segundo Brunton LL e Goodman G (2012), a HU é metabolizada no fígado, podendo gerar elevações nos níveis das transaminases. De acordo com Cancado RD, et al. (2009), recomenda-se a monitorização das transaminases devido a potencial toxicidade hepática, tanto que a dosagem de transaminases faz parte do protocolo proposto pela portaria n०55/2010.

Avaliando os resultados dos valores de Ácido Úrico, foi possível avaliar apenas os dados até o $4^{\circ}$ trimestre. Tal fato se justifica pelo fato de que a unidade de assistência farmacêutica onde os dados foram coletados não exigia os resultados do ácido úrico para os pacientes em uso de $\mathrm{HU}$, apesar de essa recomendação ser citada na Portaria n०55/2010. Com os resultados obtidos, foi observado um discreto aumento nas taxas médias nominais em todos os semestres (Tabela 3), com um aumento percentual de aproximadamente $20 \%$ em relação ao valor controle no $4^{\circ}$ semestre. De acordo com Brasil (2012), a HU pode provocar aumentos nos níveis de ácido úrico, e ressalta a importância do monitoramento deste marcador. O aumento nos níveis de ácido úrico foi observado nos resultados obtidos, apesar da falha no banco de dados do local da coleta.

Quanto aos níveis de Hemoglobina Fetal, observou-se um aumento considerável nas taxas de HbF após o uso da HU (Tabela 3), sendo que em alguns trimestres, o aumento chegou a índices maiores que $100 \%$ do valor original. Tal elevação nas taxas de HbF era esperada, pois Conforme Pedrosa, 2014, a HU tem a propriedade de aumentar a síntese intraeritrocitária de $\mathrm{HbF}$, o que é fator de proteção para diminuição das crises álgicas. "A HU age principalmente, aumentando a produção de $\mathrm{HbF}$ em eritrócitos que contém essa hemoglobina, alterando assim a cinética e a dinâmica de polimerização da $\mathrm{HbS}$ inibindo, consequentemente, o processo de falcização intracelular e a hemólise" (SANTOS BSC, 2011). Resultados semelhantes foram obtidos nos estudos de Bispo IMGP (2013), Silva-Pinto AC, et al. (2013) e Laurentino MR (2016), mostrando o aumento significativo da $\mathrm{HbF}$ nos pacientes portadores de AF em tratamento com a hidroxiureia.

\section{CONCLUSÃO}

A idade média dos pacientes que utilizam a HU na cidade de Teresina, Piauí, é de 15,28 anos, com predomínio de indivíduos do sexo masculino e o uso da droga é capaz de causar alterações dos índices

REAS/EJCH | Vol.Sup.n.40 | e2801 | DOI: https://doi.org/10.25248/reas.e2801.2020 Página 8 de 9 
hematimétricos da série vermelha. Na série branca, o uso da HU também mostrou mielotoxicidade, induzindo leucopenia e plaquetopenia em função do tempo de tratamento na população estudada. Além disso, o uso da HU é capaz de alterar os níveis dos marcadores bioquímicos. O conhecimento do perfil da toxicidade mostrou ser uma importante ferramenta para melhora do manejo clinico de pacientes portadores de anemia falciforme em uso de $\mathrm{HU}$, por apresentar os principais parâmetros hematológicos e bioquímicos que sofrem influência direta do uso deste fármaco.

\section{REFERÊNCIAS}

1. ALMEIDA PM, et al. Genotoxic potential of the latex from cotton-leaf physicnut (Jatropha gossypiifolia L.). Genetics and Molecular Biology, 2015; 38: 93-100.

2. ARAÚJO TME, et al. Caracterização dos casos de anemia falciforme em uma microrregião do estado do Piauí. Revista de Pesquisa: Cuidado e Fundamental (Online), 2011; 3: 199-207.

3. BISPO IMGP. Avaliação dos parâmetros hematológicos e incidência de episódios decorrentes de vaso oclusão na pessoa com anemia falciforme, antes e depois do tratamento com hidroxiureia, MS. Dissertação (Mestrado Saúde e Desenvolvimento). Universidade Federal do Mato Grosso do Sul, Campo Grande, 2013; 71 p.

4. BRASIL. 2010. In: Ministério da Saúde. Portaria n 55. Brasília, 29 de Janeiro de 2010. Disponível em: http://www.saude.mt.gov.br/upload/legislacao. Acesso em: 10 set. 2017.

5. BRASIL. 2012. In: Ministério da Saúde. Secretaria de Atenção à Saúde. Departamento de Atenção Especializada. Doença falciforme: condutas básicas para tratamento. Disponível em: http://bvsms.saude.gov.br/bvs/publicacoes/doenca_falciforme_condutas_basicas. Acesso em: 12 set. 2017.

6. BRASIL. 2013. In: Ministério da Saúde. Departamento de Gestão e Incorporação de Tecnologias em Saúde da Secretaria de Ciência, Tecnologia e Insumos Estratégicos. hidroxiureia para crianças com doença falciforme. Comissão Nacional de Incorporação de Tecnologias no SUS (CONITEC) - Relatório $n^{\circ}$ 57, 2013. Disponível em: http://conitec.gov.br/images/Consultas/Relatorios/2016/Relatorio_PCDT_DoencaFalciforme_CP_2016_v2. Acesso em: 12 set. 2017.

7. BRUNTON LL, GOODMAN G. As Bases Farmacológicas da Terapêutica. 12ª ed. Rio de Janeiro: McGraw-Hill, 2012 ; $2112 \mathrm{p}$.

8. CANCADO RD, et al. Protocolo clínico e diretrizes terapêuticas para uso de hidroxiureia na doença falciforme. Rev. Bras. Hematol. Hemoter. 2009; 31: 361-366.

9. FURTADO NA, et al. Estudo do perfil dos pacientes portadores de Síndromes Falciformes acompanhados no Serviço de Hematologia do Centro Estadual de Hemoterapia e Hematologia do Espírito Santo (HEMOES). Revista Brasileira de Pesquisa em Saúde, 2015; 16: 1-8.

10. GOMES IBS. Avaliação dos parâmetros hematológicos e bioquímicos de voluntários sadios da Unidade de Farmacologia Clínica da UFC, CE. Dissertação (Mestrado em Farmacologia) - Universidade Federal do Ceará, Fortaleza, 2003; $114 \mathrm{p}$.

11. LAURENTINO MR. Relação entre polimorfismos do gene BCL11A e biomarcadores de hemólise em pacientes com anemia falciforme, CE. Tese (Doutorado em Patologia) - Universidade Federal do Ceará, Fortaleza, 2016 ; 57 p.

12. LEAL KST, et al. Relação entre os valores do vcm e do rdw-cv em hemogramas de pacientes atendidos no laboratório de análises clínicas do hospital das clínicas em Itaperuna-RJ. Acta Biomedica Brasiliensia, 2015; 6: 59-67.

13. MARTINS PRJ, et al. Morbimortalidade em doença falciforme. Rev. Bras. Hematol. Hemoter, 2010; 32: $378-383$.

14. SANTOS BSC. Impacto da terapia com a hidroxiureia e dos haplóticos no perfil oxidativo na anemia falciforme. CE. Dissertação (Mestrado em Patologia) - Universidade Federal do Ceará, Faculdade de Medicina, Fortaleza, 2011,96 p.

15. SILVA MC, SHIMAUTI ELT. Eficácia e toxicidade da hidroxiureia em crianças com anemia falciforme. Revista Brasileira de Hematologia e Hemoterapia, 2006; 28: 144-148.

16. SILVA-PINTO AC, et al. Clinical and hematological effects of hydroxyurea therapy in sickle cell patients: a singlecenter experience in Brazil. Sao Paulo Med. J, 2013; 131: 238-243.

17. SOARES LF, et al. Prevalência das hemoglobinas $\mathrm{S}$ e $\mathrm{C}$ em heterozigose em duas comunidades de povos de terreiros na cidade de Teresina, Piauí. Revista de Ciências Farmacêuticas Básica e Aplicada, 2014; 36: 91-95.

18. SOUZA JM, et al. Fisiopatologia Da Anemia Falciforme. Revista Transformar, 2016; 8: 162-178. 